\title{
A minimização da formação dos jovens brasileiros: alterações do ensino médio a partir da lei 13415/2017
}

\author{
Sandra Regina Oliveira Garcia* \\ Universidade Estadual de Londrina \\ Eliane Cleide Silva Czernisz** \\ Universidade Estadual de Londrina
}

Resumo $\mathrm{O}$ artigo tem como objetivo discutir as alterações do ensino médio que vêm se concretizando, a partir da aprovação da Lei 13415/2017. Analisa o contexto e interesses norteadores das proposições da referida Lei e discute a proximidade com orientações internacionais relativas à formação para o trabalho da juventude brasileira. É um assunto importante para reflexão dos educadores que têm discutido o ensino médio, a relação entre trabalho e educação e a formação da juventude brasileira. Desenvolvido com base em discussão bibliográfica e documental, procura responder: que orientações norteiam a atual reforma do ensino médio? Quais são os limites e as possibilidades com a implementação dessa proposta reformista? Como resultados da análise, destaca que as mudanças em curso a partir de tal legislação mantêm os interesses de formação direcionada ao mercado, impossibilitando uma formação integral e o efetivo desenvolvimento educacional do ensino médio no país.

PALAVRAS-ChaVE: Ensino médio; Trabalho; Educação; Juventude. 


\title{
The minimization of the training of young brazilians: changes in middle school as from law 13415/2017
}

\begin{abstract}
The article aims to discuss the alterations of high school that been coming to fruition, since the approval of Law 13415/2017. It analyzes the context and interests of the proposals of the referred Law and discusses the proximity with international guidelines relative to formation for Brazilian youth work. It is an important subject for reflection of educators who have discussed high school, the relationship between work and education and the formation of Brazilian youth. Developed on the basis of bibliographical and documentary discussion, it tries to answer: what orientations guide the current reform of high school? What are the limits and possibilities with the implementation of this reform proposal? As a result of the analysis, it highlights that the changes under way from such legislation keep the interests of training directed to the market, making it impossible for a comprehensive education and the effective educational development of high school in the country.
\end{abstract}

KEYWORDS: High School; Work; Education; Youth.

\section{Introdução}

O Ensino Médio brasileiro, etapa que tem sofrido muitas mudanças, quando analisamos o histórico de seu desenvolvimento, passa novamente por alteração curricular. As redefinições curriculares do Ensino Médio têm sido realizadas em momentos bastante estratégicos para direcionamento da sociedade brasileira, explicitando os interesses governamentais acoplados aos intentos de perpetuação capitalista. Apesar de tais argumentos, o processo que envolve a nova lei do Ensino Médio tem sido pautado inicialmente na crítica à quantidade de disciplinas do atual currículo do Ensino Médio e na defesa de que os jovens precisam definir sua carreira profissional com mais liberdade, dando a entender que havia um engessamento curricular impossibilitando sua inserção no mercado de trabalho. Estas questões têm sido explicitadas em propagandas governamentais que expressam a concordância da sociedade brasileira. Mas, em que pese o discurso veiculado, faz-se necessário levantar outras questões para este debate, que, neste texto, são consideradas imprescindíveis para contribuir com o esclarecimento, não apenas do sentido assumido pelas recentes alterações curriculares, como também do seu impacto na vida dos estudantes. Por tais razões, este texto questiona: qual o sentido das alterações curriculares do ensino médio? Quais as perspectivas e os limites impostos pela Lei 13415/2017 para os jovens do Ensino Médio?

Diante dos questionamentos apresentados, propomos como objetivos do presente texto discutir as alterações do Ensino Médio, a partir da Lei 13415/2017, e refletir sobre as perspectivas e limites da mesma. Para dar conta do pretendido, utilizamos pesquisa bibliográfica e tomamos por base as discussões de pesquisadores que, historicamente, têm acompanhado o Ensino Médio. Também nos valemos de 
dados documentais por compreender que as indicações de normativas explicitam as intencionalidades que emergem num determinado período visando a concretizar um projeto de sociedade e de educação. $\mathrm{O}$ texto se organiza apresentando, num primeiro momento, as proposições de alterações do Ensino Médio; num segundo, destacamos a aproximação das alterações observadas na nova Lei com as indicações de organismos internacionais; num terceiro momento trazemos considerações sobre o significado da estruturação curricular do Ensino Médio com a Base Nacional Curricular Comum BNCC; e finalizamos, destacando os limites da atual Lei para a juventude brasileira.

\section{Proposições da reforma do ensino médio}

O ensino médio tem se tornado o centro de discussões e interesses neste momento em que passa por nova alteração, a qual vem sendo questionada por pesquisadores brasileiros que há muitos anos estão envolvidos com a questão e discordam do atual encaminhamento. Antes de prosseguir com a análise, é importante mencionar o alerta feito por Ferreira (2017) de que o termo reforma não poderia estar sendo utilizado para caracterizar as transformações do ensino médio decorrentes da Lei 13415/2017. A autora ressalta que o termo deveria ser contrarreforma do ensino médio já que o termo reforma, de acordo com seus estudos, pertence ao campo da esquerda. Entendemos que a reforma, no sentido discutido pela autora, possibilitaria conquistas sociais aos jovens brasileiros. Como percebemos, as alterações curriculares provenientes da Lei 13415/2017 trazem mais retrocesso e perdas sociais que conquistas.

$\mathrm{Na}$ atual reforma, pela Lei 13415/2017, é possível verificar claras intenções de aproximação da formação com as demandas do mercado de trabalho. Nesse sentido, é importante retomar as análises de Ferretti (2016, p. 72) que ressalta que as alterações que têm ocorrido no ensino médio têm envolvido a "[...] estrutura e conteúdo do currículo [...]". O autor contribui para pensar os diferentes momentos em que, na história da educação brasileira, foram feitas alterações curriculares, por exemplo, o que é considerado por ele como "primórdios do que hoje conhecemos por Ensino Médio" (FERRETTI, 2016, p. 72). Das análises desenvolvidas por Ferretti, destacamos as que ocorreram entre as décadas de 1960 e 1970, caracterizadas por forte influência da Teoria do Capital Humano, como a profissionalização compulsória da Lei 5692/71. Também evidenciamos a LDB 9394/96 que, após aprovada, teve a regulamentação da educação profissional pelo Decreto 2.208/97. Observamos que as alterações ocorridas no período, apesar de guiarem-se pelas preocupações em formar para atender ao contexto econômico de mudanças das forças produtivas, explicitam as contendas entre posições diferentes de defesas da formação média. Este embate fica claro nas análises de Ferretti (2016).

A disputa por um ensino médio que possibilitasse a integração entre a formação geral e a profissional pode ser percebida nas discussões que nortearam a revogação do Decreto 2.208/97 com a aprovação do Decreto 5.154/2004. Com este novo encaminhamento, tornou-se possível retomar um projeto pedagógico embasado na defesa da formação que contemplava, para além das intenções de formação para o trabalho, também a formação científica, necessária aos estudantes filhos de trabalha- 
dores da classe menos favorecida. Esta linha orientadora também pode ser observada em 2012, quando foram homologadas as atuais Diretrizes Curriculares Nacionais do Ensino Médio - DCNEM e Diretrizes Curriculares Nacionais da Educação Profissional de nível Técnico - DCNEPT. Apesar de grandes contradições entre as duas, as DCNEM definem claramente que esta etapa deve ter um currículo integrado e que as dimensões do trabalho, ciência, cultura e tecnologia são indissociáveis no processo formativo.

Apesar de a aprovação das DCNEM ter sido considerada um avanço, pouco foi feito para a sua materialização, o que pode ser comprovado com a criação no Congresso Nacional de uma Comissão de deputados que tomaram para si a elaboração de uma proposta de reforma do ensino médio, que culminou, em 2013, com apresentação e início de tramitação do PL no 6840/2013. Este projeto de lei desconsiderou todo o processo de discussão para elaboração das diretrizes, que foi coordenado pelo Conselho Nacional de Educação - CNE.

O PL no 6840 apontou, como direção, a proposta do ensino médio em tempo integral com a justificativa de que "[...] se possam desenvolver adequadamente as possibilidades formativas", passando de $2.400 \mathrm{~h}$ atuais para $4.200 \mathrm{~h}$. Assumiu o discurso de que 13 disciplinas era um número excessivo e, portanto, propôs a flexibilização do currículo com a sua organização por áreas de conhecimento, em que o aluno poderia escolher o seu itinerário formativo, segundo o que consta na justificativa do PL para torná-lo mais atraente para os alunos.

A necessidade de readequação curricular no ensino médio, de forma a torná-lo atraente para os jovens e possibilitar sua inserção no mercado de trabalho, sem que isso signifique o abandono da escola, foi, sem dúvida, o ponto mais debatido nas reuniões da CEENSI. O consenso foi de que o atual currículo do ensino médio é ultrapassado, extremamente carregado, com excesso de conteúdos, formal, padronizado, com muitas disciplinas obrigatórias numa dinâmica que não reconhece as diferenças individuais e geográficas dos alunos. Há que se ampliarem as possibilidades formativas do ensino médio, de modo a torna-lo adequado às necessidades do jovem de hoje, atraindo-o para a escola. (PL nº6840/13).

Outro destaque do PL é que define que a formação dos professores deveria ser também realizada por áreas de conhecimento (linguagens, matemática, ciências da natureza, ciências humanas), o que faria com que a contrarreforma do ensino médio promovesse uma alteração dos cursos de licenciatura no ensino superior, como podemos verificar no excerto:

Para a efetivação desta determinação, estabelecemos, também, que a formação dos docentes para o ensino médio se dê a partir dessas quatro áreas do conhecimento, de forma a habilitar os professores a tratarem adequadamente os conteúdos e permitir seu aprofundamento. (PL no 6840/13).

Em relação à educação profissional, abre a possibilidade de as escolas e sistemas de ensino realizarem parcerias com o setor produtivo, segundo explicam, "maior interessado na formação de técnicos". Tais parcerias serão analisadas adiante neste 
texto, mas gostaríamos de adiantar que este direcionamento confirma o interesse do setor privado nesta etapa educativa como possibilidade de formar na escola pública a mão de obra necessária ao setor produtivo.

Como se constata, o PL recupera o que nos anos 90 já se apontava para o ensino médio brasileiro, e que, com o impeacbment da presidenta Dilma em 2016, é retomado pelo grupo que toma posse no MEC, os mesmos que estavam na década de 1990 neste ministério. Desconsideram os 13 anos de políticas/programas educacionais deste período (Lula e Dilma) e também encontraram um campo fértil já desencadeado pelo PL no 6840. Neste sentido, assim que assumem, apresentam, a MP no $746 / 2016$ que recupera o teor do que estava presente no PL, pois os mesmos foram os principais interlocutores no processo de discussão na Comissão Especial da Câmara. Este dado comprova que as mudanças propostas já vinham sendo pensadas desde 2011 com a constituição da Comissão no Congresso Nacional.

\section{A Lei 13415/2017 e a similaridade com as propostas de or- ganismos internacionais}

As mudanças curriculares pressupõem concepções novas tanto no direcionamento do tipo de homem que será formado quanto na redefinição do significado que passa a ter cada etapa educativa. Com esta afirmativa, destacamos que qualquer redefinição curricular diz respeito às concepções, à visão de sociedade e à de educação. No caso do ensino médio, várias são as modificações. Como podemos ver, o texto da Lei 13415/2017 modifica a proposta de formação do ensino médio, alterando a LDBEN 9394/96. Dentre as mudanças, destacamos o artigo 35 com a inserção da Base Nacional Comum Curricular, organizando o currículo por áreas de conhecimento "I Linguagens e suas tecnologias; II Matemática e suas tecnologias; III Ciências da Natureza e suas tecnologias; IV Ciências Humanas e Sociais Aplicadas".

Com a inserção da base, conforme determina a Lei, a "educação física, arte, sociologia e filosofia" serão incluídas como estudos e práticas. A demarcação da inclusão destes conhecimentos enfatizados como inserção obrigatória possibilita compreender que foram aí, forçosamente, inseridos, pois, conforme já vimos nas discussões da MP 746, havia a intencionalidade de retirar tais conhecimentos, aspecto causador de questionamentos e incertezas a respeito deste assunto. A Lei também definiu a obrigatoriedade de contemplar a língua inglesa, deixando a língua espanhola como optativa preferencial, um direcionamento que desconsidera a realidade de um país que tem fronteira com países de idioma espanhol.

O artigo 35 também menciona a formação integral, cujo sentido destoa das defesas pela educação integral com fundamentação emancipatória, como podemos ver no trecho a seguir:

$\S 7^{\circ}$ Os currículos do ensino médio deverão considerar a formação integral do aluno, de maneira a adotar um trabalho voltado para a construção de seu projeto de vida e para sua formação nos aspectos físicos, cognitivos e socioemocionais. 
Cabe às redes de ensino, segundo o $\S 8$, organizar as formas como ocorrerão as atividades, como serão encaminhados os "conteúdos, as metodologias e as formas de avaliação processual e formativa (...)". Tais procedimentos são necessários para possibilitar, conforme destaca a Lei nos incisos I e II do mesmo parágrafo:

$$
\begin{aligned}
& \text { I - domínio dos princípios científicos e tecnológicos que presidem } \\
& \text { a produção moderna; } \\
& \text { II - conhecimento das formas contemporâneas de linguagem. }
\end{aligned}
$$

A formação técnica e profissional no ensino médio será realizada mediante itinerários formativos. Essa menção é feita no artigo $36 \S 6^{\circ}$ que, nos incisos I e II, especifica:

I - a inclusão de vivências práticas de trabalho no setor produtivo ou em ambientes de simulação, estabelecendo parcerias e fazendo uso, quando aplicável, de instrumentos estabelecidos pela legislação sobre aprendizagem profissional;

II - a possibilidade de concessão de certificados intermediários de qualificação para o trabalho, quando a formação for estruturada e organizada em etapas com terminalidade.

A Lei abre possibilidade para que outros atores entrem no processo da formação. Além de oportunizar, como fato novo os itinerários formativos, também deixa margem para cumprir com a formação recorrendo a outras formas educativas, como podemos ver no artigo $36, \S 11$, incisos I a VI.

$\S 11$. Para efeito de cumprimento das exigências curriculares do ensino médio, os sistemas de ensino poderão reconhecer competências e firmar convênios com instituições de educação a distância com notório reconhecimento, mediante as seguintes formas de comprovação:

I - demonstração prática;

II - experiência de trabalho supervisionado ou outra experiência adquirida fora do ambiente escolar;

III - atividades de educação técnica oferecidas em outras instituições de ensino credenciadas;

IV - cursos oferecidos por centros ou programas ocupacionais;

$\mathrm{V}$ - estudos realizados em instituições de ensino nacionais ou estrangeiras;

VI - cursos realizados por meio de educação a distância ou educação presencial mediada por tecnologias.

Verifica-se, por este artigo, que o ensino médio se abre para parcerias com outras instituições e atores. Contraditoriamente à ênfase na formação integral, com o reforço à obrigatoriedade do ensino de língua portuguesa e de matemática, aspecto que consideramos requerer profissionais licenciados, também observamos uma flexibilização tanto do conhecimento quanto da contratação de professores, já que a exigência da formação específica na docência é desconsiderada com a indicação de profissionais com notório saber para atuar no ensino médio, como estabelece o inciso IV do artigo 
61. Lembramos, no entanto, que a formação do professor é fundamental para atuação docente e para mediação pedagógica no que diz respeito ao trabalho com o currículo, ao projeto político pedagógico, ao planejamento, à avaliação, e para a própria relação entre professor e aluno que exige conhecimentos sobre a peculiaridade do desenvolvimento e aprendizagem humana. Logo, vemos que ensinar não exige apenas técnica: exige um saber científico que norteia atividades de ensino e que, enquanto professores, devemos nos negar a desconsiderá-lo.

Não é simples coincidência que a Faculdade de Educação do SESI, em 2016, tenha aberto seleção para formação de professores por área de conhecimento, ou seja, a fim de contemplar os docentes considerados necessários ao atendimento do ensino médio nesta nova legislação. Cumpre ressaltar que a formação integral prevista nesta legislação atende aos requisitos de mercado. É integral na perspectiva mercadológica, porque possibilitará um tipo de educação que preparará o trabalhador necessário à realidade competitiva.

O resultado será uma educação direcionada às demandas competitivas do mercado local, o que deixará o estudante em desvantagem frente a outros estudantes de países que privilegiarão os conhecimentos construídos e acumulados historicamente pela humanidade. Esta defasagem, provocada por um ensino voltado para o fazer, pesará no futuro quando um aluno brasileiro precisar continuar estudando em outro país e não conseguir acompanhar o currículo estabelecido, porque sua escolarização tivera como foco conhecimentos práticos, em detrimento dos conteúdos, que são direito de toda a humanidade. Isso ocorrerá pela falta de conhecimento de outras línguas estrangeiras, pela redução e até pela ausência de discussão suscitada pelas disciplinas de filosofia e sociologia, pela secundarização dos conhecimentos sobre as artes, pois entendemos que a arte é criação humana, é história, que revela todo um processo de reflexão e expressão do homem diante do mundo, em cada etapa de desenvolvimento da humanidade. Não se trata, porém, de desvalorizar os conhecimentos de português e matemática. O que se defende é que estes estejam acompanhados de outros, igualmente essenciais para a formação holística do cidadão. Se assim não for, serão apenas recursos empregados para se passar em testes que valorizam mais a performance escolar do que uma formação, verdadeiramente integral.

Também ressaltamos o equívoco relacionado à educação integral. Pelo que temos no texto da Lei, o instituído no artigo 13 é a "Política de Fomento à Implementação de Escolas de Ensino Médio em Tempo Integral", para as quais se estabelece a destinação de recursos federais. Vejamos que ocorre a ampliação do tempo de permanência na escola e que isso instaura o ensino médio em tempo integral. Observamos que as indicações estabelecidas para o ensino médio na nova Lei reforçam a formação que contempla o mercado tanto como área de atuação como também como parceiro no desenvolvimento do ensino médio. O reforço aos itinerários formativos, ao notório saber e à experiência como norteadores da formação são itens que requerem atenção. Observa-se haver reivindicação de formação em tempo integral, o que nos leva a questionar como ficará a formação do estudante que já trabalha. Esta questão é preocupante pelo risco que se corre de supressão de vagas no ensino médio noturno, embora o direito à educação não possa ser negado. 
Algumas indicações para este processo já vinham sendo dadas por organismos internacionais como a UNESCO (2008) e a OCDE e CEPAL (2017). Verificamos que em ambos os documentos a perspectiva é uma formação que vislumbra $o$ reforço da prática e das habilidades profissionais. No documento da UNESCO (2008) a perspectiva é estreitar a formação com prática e com treinamento. Para tanto, também menciona que:

As escolas secundárias podem adotar modelos flexíveis de ensino e de uso do tempo, e as empresas locais - industriais, agrícolas e de serviços - podem associar-se por meio de sistema de estudo-trabalho, de cooperativas ou de programas de aprendizagem profissional. (UNESCO, 2008, p. 26).

Tal indicação é pautada, conforme se verifica no documento, na aquisição de conhecimentos necessários à vida cotidiana, que poderiam ser desenvolvidos no ensino secundário. Pelo documento, entendemos estar claro o objetivo da formação secundária sugerida:

Tal modelo de educação secundária deveria proporcionar aos jovens múltiplas habilidades que os tornem capazes de se integrarem à força de trabalho - e, se necessário for, a se reintegrar por mais de uma vez ao longo de sua vida profissional -, seja como assalariados ou empreendedores autônomos, de se formarem novamente quando suas habilidades se tornem obsoletas e a participarem de maneira sustentável em seu próprio desenvolvimento econômico e social bem como no desenvolvimento da própria comunidade. (UNESCO, 2008, p. 29).

Percebemos, também, no documento "Perspectivas Económicas de América Latina 2017: juventude, competencias y emprendimiento" (OCDE, CEPAL, CAF, 2017), que são fortes as indicações para aproximação da formação no ensino médio daquela que tem sido requisitada pela iniciativa privada. O documento apresenta uma análise do desenvolvimento econômico e social da América Latina, discutindo de que forma o jovem tem se inserido em atividades produtivas. Também demonstra grande preocupação com a inclusão dos jovens no mercado de trabalho devido ao envelhecimento da população, e aos riscos econômicos como o não rendimento do mercado até o risco pessoal para o jovem com seu envolvimento em violência e sua falta de participação nas esferas política e social. $O$ documento considera que o investimento nos jovens é fundamental para o desenvolvimento de uma sociedade mais igualitária e destaca a preocupação com a taxa de jovens que se evadiram da escola:

La tasa de jóvenes latinoamericanos que no están empleados y no cursan estudios ni reciben capacitación es un buen indicador de la realidad educativa y del mercado laboral juvenil, que refleja tanto el riesgo del desempleo como la inactividad. Como tal, más que con el desempleo juvenil, podría estar vinculada estrechamente con el riesgo de marginación a largo plazo del mercado laboral y la exclusión social, aunque ambos indicadores en gran medida se solapan. Los responsables de la formulación de políticas también deberían prestar atención a la tasa de jóvenes latinoamericanos que no están empleados, no estudian, no reciben capacitación , tanto por su importancia como único objetivo específico para la juventud contenido 
en los Objetivos de Desarrollo Sostenible (ODS) posteriores a 2015 como por la adopción del objetivo por parte del G20 de reducir la proporción de jóvenes con mayor riesgo de quedarse fuera del mercado laboral en un $15 \%$ para el año 2025.(OCDE, CEPAL, CAF, 2017, p. 104).

Segundo o documento, há uma preocupação com a escolarização vinculada à inserção ao mundo do trabalho. Ressaltamos, no entanto, que esta não é a única forma de se conceber a escolarização, enquanto necessária a crianças e jovens latino-americanos.

Muitos pesquisadores brasileiros têm debatido a escolarização dos jovens, colocando o assunto como pauta de inúmeras discussões que priorizam o fato de que a democratização da educação básica não pode envolver apenas a preocupação com o ingresso no mercado de trabalho, posto que lutam também por uma questão anterior a esta: o direito à educação. Destacamos, ainda, os esforços para a universalização da educação básica, a luta pelo direito à educação e a constante reivindicação de investimento público para que a educação básica seja realmente exequível. Dados desta constante batalha podem ser observados em normativas como a Constituição Brasileira (1988) e o Plano Nacional de Educação - Lei 13005/2014.

O documento da CEPAL informa que hoje os jovens da América Latina são mais educados, possuem maior quantidade de anos de escolarização que as gerações anteriores e que a expansão da educação na região latino-americana favoreceu principalmente os jovens pobres. Reforça a importância de conhecimentos como português, matemática e ciências e comenta o baixo desempenho dos jovens da América Latina no PISA. Reconhece que, para a formação profissional, seria muito importante que a formação ocorresse também no posto de trabalho e destaca:

La educación y las competencias son cruciales para respaldar la inclusión de los jóvenes y su participación exitosa en el mercado de trabajo. La calidad de la educación, que procura competencias básicas y técnicas, proporciona a los jóvenes herramientas para participar y disfrutar plenamente de la vida adulta. Además, constituye uno de los principales instrumentos para garantizar la inclusión social, política y productiva de los jóvenes en la sociedad.

Pese a los notables avances realizados, el acceso de la población a la educación y las competencias en ALC sigue siendo deficientes. La calidad y pertinencia de la educación y las capacidades ofrecidas por los sistemas educativos en la región son un problema crucial. Hay indicios de escasez de competencias requeridas por los empleadores. Mientras la educación tradicional va a la zaga en términos de competencias básicas de lectura, matemáticas y ciencias; la EFTP, centrada en sectores obsoletos y de baja calidad, no constituye una solución viable para subsanar las deficiencias de la población joven en materia de competencias. Además, la falta de vínculos entre la educación y la demanda de competencias de los mercados laborales es otro gran motivo de preocupación. (OCDE, CEPAL, CAF, 2017, p. 208). 
As preocupações evidenciadas nos documentos da Unesco (2008) e da OCDE e CEPAL (2017) aproximam-se, em nosso entendimento, daquelas que podemos observar na Lei 13415/2017, que reforma o ensino médio. Verificamos a ênfase na aprendizagem de português e matemática, e atribuímos tal preocupação ao aferimento de índices de qualidade nas avaliações de larga escala. Reforçamos que consideramos a importância das avaliações para além da classificação educacional de alunos, escolas, redes e países e entendemos que a avaliação implica repensar a tarefa educativa, visando ao seu aprimoramento que deve estar direcionado à efetiva aprendizagem do estudante. Também consideramos importante que, no ensino médio, haja a preocupação com a inserção profissional, embora não tenhamos o mesmo ponto de vista com relação à flexibilização curricular vinculada ao treinamento para o mercado, fato que entendemos ser prejudicial pela secundarização de conhecimentos importantes e imprescindíveis à compreensão dos estudantes sobre sua cidadania, o mundo e o lugar que ocupam neste mundo. Deste modo, reafirmamos a necessidade de aprofundar o estudo sobre o currículo voltado à formação humana plena e não a um arremedo de formação integral.

\section{A reforma do ensino médio e a centralidade do currículo na Base Nacional Comum Curricular}

A Base Nacional Comum do Currículo do Ensino Médio vem sendo elaborada por um grupo de especialistas (que a sociedade desconhece quem são) e que, mesmo sem ter sido aprovada, ganhou centralidade na reforma desta etapa da educação básica.

Apesar de a Constituição de 1988 e a Lei de Diretrizes e Bases (LDB) N. 9394/96 indicarem que a educação brasileira deve orientar-se por uma Base Nacional Comum Curricular, apenas a partir das Diretrizes Curriculares Nacionais para a Educação Básica, que foram revistas entre 2009 e 2012, é que se abriu a discussão sobre uma Base Nacional Comum do Currículo, também motivada pelas avaliações nacionais que acabavam, de alguma forma, conformando um currículo básico para as escolas por conta do peso colocado em relação às avaliações.

De alguma forma, tanto a LDB 9394/96 como as próprias Diretrizes Curriculares já apontavam o que os sistemas de ensino e as escolas devem prever em seus currículos, ou seja, o que dá unidade nacional em relação ao conhecimento escolar: conhecimentos que devem ser objetos de trabalho escolar ao longo da Educação Básica sem, no entanto, conformar estes conhecimentos em listas de conteúdos mínimos.

A discussão da BNCC, na verdade, explicitou os projetos históricos em disputa: os interesses privatistas e os interesses públicos em relação à educação. A BNCC passa a ser instrumento de controle do trabalho na escola e, consequentemente, do conhecimento que se pretende disponibilizar para a população. Em relação à disputa entre público e privado, podemos destacar a indústria de produção de materiais, uma grande beneficiada por um currículo único, assim como a indústria de avaliações que se instaurou no país, ambas defensoras desta política. Em relação à centralização por meio de um currículo único e de avaliações externas, é suprimido o protagonismo do 
professor, sua autonomia para realizar o trabalho pedagógico, passando a ser mero reprodutor do processo educativo.

A proposta ora apresentada utiliza algumas categorias como educação integral, educação de qualidade, formação humana, mas não faz o enfrentamento em relação às disputas entre uma formação humana e uma formação restrita para o trabalho imediato. Entendemos que a concepção de formação humana remete a uma educação de qualidade para todos, criando as condições para a sua materialidade e, portanto, combatendo as desigualdades. A formação voltada para o trabalho prioriza apenas a lógica do mercado e desqualifica o conhecimento pela lógica das competências e habilidades.

É fantasioso supor que a BNCC seja a chave para o enfrentamento das mazelas da educação brasileira. A garantia do direito à aprendizagem e ao desenvolvimento durante a trajetória na Educação Básica não resulta de uma oferta comum, homogênea e homogeneizante. Ao contrário, resulta da compreensão das diferenças como condições e não como déficits, o que permite organizar o trabalho escolar de forma a não excluir nenhuma criança ou jovem por sistemáticas experiências de fracasso. Uma educação que atenda a todos e que tenha como centralidade o processo de formação integral se dará quando se definir que a educação é realmente prioridade e se fizer o enfrentamento das desigualdades.

O currículo não pode ser compreendido como redentor. $\mathrm{O}$ enfrentamento passa pela discussão curricular no interior da escola, mas passa, principalmente, por atender às diferenças, respeitando-as: uma escola igual para todos, beneficia os "iguais". Para isto, é necessário assegurar escolas com infraestrutura adequada, com carreira de professores e salários condizentes com a responsabilidade, com formação inicial e continuada que correspondam aos desafios enfrentados no fazer pedagógico, que sejam providas de recursos tecnológicos, biblioteca físicas e virtuais, recursos humanos, materiais, físicos e financeiros para que os esforços convirjam para práticas de qualidade.

Neste sentido, a educação deve ser ofertada por instituições que tenham centralmente a defesa da Escola Pública, nas quais os regimes de trabalho sejam de dedicação exclusiva a elas, para que o professor seja efetivamente conhecedor do seu projeto pedagógico e comprometido com ele. Reforçando, para que o trabalho, a cultura, a ciência e a tecnologia sejam as dimensões edificadoras do currículo, é necessário inventar novos espaços de aprender e ensinar com tecnologias educacionais disponíveis a todos, de programas de iniciação cientifica para os alunos se apropriarem e produzirem conhecimentos, de espaços culturais, ou seja, onde as dimensões do trabalho, da ciência, da tecnologia e da cultura sejam intrínsecas à formação de todos. Isso porque, como pode a BNCC, a partir de tantas desigualdades, reduzi-las? O conforto de um pacote básico de conhecimento não parece ser uma boa resposta. 


\section{Os limites da proposta para a formação da juventude brasileira}

A formação da juventude brasileira passa claramente por disputas. A principal delas se refere ao tipo de conhecimento que deve ser disponibilizado para a classe trabalhadora. Entendemos que as alterações propostas para o Ensino Médio e efetivadas pela Lei no13415/17, além de serem autoritárias, propõem a redução, a minimização do conhecimento para os jovens da classe trabalhadora, que têm na escola pública o centro do seu processo formativo. Esta Lei não afetará, no entanto, a formação dos alunos que estudam em escolas privadas, por dois motivos. Primeiro, porque estas, assim como fizeram no período vigente da Lei no 5692/71, não efetivarão as mudanças propostas pela legislação, até porque, nestas instituições, há cobrança para que todos os conhecimentos sejam disponibilizados a fim de que os alunos possam continuar estudando na educação superior e até prosseguir os estudos em outros países, condições impossibilitadas, em nosso entendimento, no caso da minimização de conhecimentos resultante da concretização da nova Lei. Segundo, porque os jovens que frequentam escolas particulares têm acesso a outras formas de constituírem o que compreendemos por formação humana integral. Podem estudar línguas estrangeiras, ter acesso à formação cultural e artística, fazer viagens de turismo e de intercâmbio, praticar esportes e outras atividades físicas que possibilitem também o seu desenvolvimento corporal.

Esta Lei limita a formação dos jovens da classe trabalhadora, porque os mesmos não terão oportunidade de escolha, visto que os itinerários formativos serão definidos pelas Secretarias de Estado da Educação para cada escola, sendo que, mesmo que esta tenha o conjunto de professores de todas as disciplinas, não terá como ofertá-las, caso tenha apenas uma ou duas turmas de ensino médio. Esta é uma das principais razões do apoio do CONSED - Conselho Nacional de Secretários de Estado de Educação - à reforma, uma solução simplista para falta de professores em algumas disciplinas. A escola não tendo, por exemplo, professores da área de Ciências da Natureza (Química, Física e Biologia), não ofertará este itinerário, e, assim, em relação aos outros itinerários formativos propostos.

Se aos estudantes fosse assegurada a oportunidade de escolha, o problema ainda persistiria, pois, a reforma minimiza, fragmenta a formação dos jovens, não garante a formação integral, a básica, e, portanto, nem o acesso ao conhecimento que possibilite a sua autonomia intelectual.

Outro aspecto a ser abordado é que a centralidade do currículo em português e matemática denota o compromisso do governo brasileiro com os organismos internacionais que definem, nas avaliações, o que é básico e o que é o conhecimento flexível necessário para atender às demandas do setor produtivo. De acordo com Kuenzer (2017), as cadeias produtivas precisam de trabalhadores com qualificações desiguais e diferenciadas e cabe, portanto, à escola realizar a distribuição desigual do conhecimento

Se há combinação entre trabalhos desiguais e diferenciados ao longo das cadeias produtivas, há também demandas diferenciadas e desiguais, de qualificação dos trabalhadores, que podem ser rapidamente atendidas pelas estratégias da aprendizagem flexível, o que 
permite que as contratações sejam definidas a partir de um perfil de trabalhador com aportes de educação geral e capacidade para aprender novos processos, e não a partir da qualificação. (KUENZER, 2017, p. 340).

A oferta do quinto itinerário formativo, a educação profissional, retoma os princípios contidos no decreto $\mathrm{n}^{\circ} 2.208 / 97$, um retorno à reforma dos anos 90 e uma abertura para a privatização.

A nova legislação cria uma grande contradição, quando trata da contratação de professores por notório saber, voltados inicialmente para a educação profissional, mas que, no entanto, cria a possibilidade de ser adotada como parâmetro para a Educação Básica, pois a formação de professores teve novas Diretrizes Curriculares Nacionais para a Formação Inicial e Continuada dos Profissionais do Magistério da Educação Básica aprovadas em 2015, Parecer no 02/15, com o intuito de valorizar a formação destes profissionais. Aqui assume o sentido da desprofissionalização do professor, notadamente se constituindo uma política de precarização da formação e do trabalho docente.

\section{Considerações finais}

Mesmo que o ensino médio seja uma conquista recente no Brasil, a luta dos trabalhadores pela educação remonta longa data. O ensino médio vem sendo disputado por vários setores da sociedade, a partir da ampliação do acesso a esta etapa aos filhos dos trabalhadores. Passamos de aproximadamente 5 milhões de matrículas em 1995 para 8 milhões em 2016 (Censo INEP - 2016). Se ainda compararmos estes dados a 1991, quando eram apenas 3 milhões de estudantes que chegavam ao ensino médio, o crescimento foi substantivo, mas não foi acompanhado de uma política efetiva.

O ensino médio tem sido visado pelo empresariado que busca na formação do trabalhador o apoio para implementação do processo de trabalho. Deste modo defende uma formação mínima que lhe garanta a perpetuação da mão-de-obra que atenda os interesses do setor produtivo em contraposição à formação integral. Entendemos então que a reforma tem sido apresentada como salvadora da pátria nesse momento em que não vai resolver a escassez de oportunidades de trabalho que são inexistentes até para quem tem formação.

O que podemos considerar dos argumentos aqui apresentados é que as alterações em curso com a Lei 13415/2017 fazem retornar para o ensino médio uma característica tecnicista. Pela perspectiva da Lei tanto os alunos terão mais oportunidades de trabalho com esse formato de ensino médio quanto as escolas teriam um funcionamento relacionado as necessidades do mercado de trabalho. Vemos que não há rompimento da visão burguesa de escola e conhecimento necessário à escola pública que atende aos filhos dos trabalhadores. Logo entendemos tratar-se mesmo de uma contrarreforma que objetiva a manutenção da escola, do conhecimento e da sociedade sobre os jugos reprodutivistas da classe no poder que, infelizmente, desconsidera o acúmulo das discussões e conhecimento sobre o ensino médio construídos ao longo da 
história no Brasil. Cabe aos educadores envolvidos o efetivo acompanhamento, análise e crítica para que possamos pensar sim numa reforma que contemple os anseios históricos da classe trabalhadora de uma educação média com conteúdo integral que vise a formação humana.

\section{Referências}

Brasil. Câmara dos Deputados. Projeto de Lei no6840/13. Disponível em: <http://www.camara. gov.br/proposicoesWeb/prop_mostrarintegra?codteor=1200428 >. Acesso em: 23 ago. 2017.

BRASIL. Ministério da Educação. Lei 13.005 de 25 de junho de 2014. Plano Nacional de Educação - PNE e dá outras providências. Diário Oficial da União. Brasília: República Federativa do Brasil. 2014. p. 2-7.

BRASIL. Constituição (1988). Constituição da República Federativa do Brasil. Promulgada em 05 de outubro de 1988. Disponível: <http://www.planalto.gov.br/ccivil_03/Constituicao/ Constituicao.htm>. Acesso em: 17 jan. 2017.

BRASIL. Casa Civil. Lei no 13.415, de 16 de fevereiro de 2017. Altera as Leis nos 9.394, de 20 de dezembro de 1996, que estabelece as diretrizes e bases da educação nacional, e 11.494, de 20 de junho 2007, que regulamenta o Fundo de Manutenção e Desenvolvimento da Educação Básica e de Valorização dos Profissionais da Educação, a Consolidação das Leis do Trabalho CLT, aprovada pelo Decreto-Lei no 5.452, de 1o de maio de 1943, e o Decreto-Lei no 236, de 28 de fevereiro de 1967; revoga a Lei no 11.161, de 5 de agosto de 2005; e institui a Política de Fomento à Implementação de Escolas de Ensino Médio em Tempo Integral. (Conversão da Medida Provisória no 746, de 2016). Brasília, 2017. Disponível em: <http://www.planalto.gov. br/ccivil_03/_ato2015-2018/2017/lei/L13415.htm>. Acesso em: 28 mar. 2017.

CNE/CP. Diretrizes Curriculares Nacionais para a Formação Inicial e Continuada dos Profissionais do Magistério da Educação Básica. Disponível em: <http://portal.mec.gov.br/index. php?option=com_docman\&view=download\&alias $=17625-$ parecer - cne - cp $-2-2015$-aprovado 9-junho-2015\&category_slug=junho-2015-pdf\&Itemid=30192>. Acesso em: 30 ago. 2017.

FERREIRA, Elza Bartalozzi. A contrarreforma do ensino médio no contexto da nova ordem e progresso. Campinas: Educação e Sociedade, v. 38, n. 139, p. 293-308, abr-jun, 2017.

FERRETTI, Celso J. Reformulações do Ensino Médio. In: Revista Holos, IFRN, 2016. n. 32, v. 6. p. 71-91. Disponível em: <http://www2.ifrn.edu.br/ojs/index.php/HOLOS/issue/ view/109>. Acesso em: 24 jun. 2017.

KUENZER, A.Z. Trabalho e escola: a flexibilização do Ensino Médio no contexto da acumulaçãoflexível. 2017. Disponível em: <http://www.scielo.br/scielo.php?script=sci_abstract\&pi$\mathrm{d}=$ S0101-73302017000200331\&lng=en\&nrm=iso\&tlng=pt $>$. Acesso em: 28 ago. 17.

OCDE.CEPAL.CAF. Perspectivas Económicas de América Latina 2017: juventud, competencias y emprendimiento. OECD, Oublishing Paris. Disponível em: <https://www.oecd.org/ dev/americas/E-book_LEO2017_SP.pdf>. Acesso em: 26 set. 2017.

UNESCO. Reforma da Educação Secundária: Rumo à convergência entre a aquisição de conhecimento e o desenvolvimento de habilidade. Brasília, UNESCO, 2008.

* Professora doutora da Universidade Estadual de Londrina, Londrina, Paraná, Brasil.

** Professora doutora da Universidade Estadual de Londrina, Londrina, Paraná, Brasil. 


\section{Correspondência}

Sandra Regina de Oliveira Garcia - Universidade Estadual de Londrina, Centro de Educação Comunicação e Artes. Campus Universitário - Rodovia Celso Garcia pr 445 Km 380. CEP: 86051990. Londrina, Paraná, Brasil.

E-mail: sandragarciapr@hotmail.com - elianecleide@gmail.com

Recebido em 10 de outubro de 2017

Aprovado em 16 de novembro de 2017 
